\title{
Rock and soil slope protection using a high stiffness geocomposite mesh system
}

\author{
D. Cheer Maccaferri S.p.a., Italy \\ G. Giacchetti Alpigeo, Italy
}

\begin{abstract}
One of the most common solutions adopted for the protection of vulnerable soil and rock slopes is wire mesh, retained by a system of anchors and ropes. Different types of meshes are available from a number of manufacturers around the world. Hexagonal 'Double Twist' type meshes have been used very successfully in civil and geotechnical engineering projects for over 60 years but in the last 10 years many alternative meshes have been brought into the market place. This can sometimes leave designers and contractors struggling to choose the most suitable mesh for their project or having to install two different meshes together in order to take advantage of specific desirable benefits, unique to each.
\end{abstract}

Recently a revolutionary geocomposite mesh Steelgrid $H R$, has been developed, which is able to offer a range of advantageous mechanical and practical benefits combined with the convenience of a single mesh. Steelgrid HR is supplied as a complete 'mesh kit' or 'system' with tried and tested installation fittings to enable the contractor, designer and client to benefit from the unique capabilities of the mesh while overcoming any conceptual ambiguity regarding system implementation. The system is available with two different corrosion protection specifications to suit a variety of different project sites from near marine environments to high alpine continental areas.

Steelgrid HR has been subjected to rigorous testing conducted by a number of highly respected independent test institutions; including testing to the new UNI 11347 standard: Tests on Meshes for Slope Coverage. This testing has allowed the Steelgrid HR system to gain both the European Technical Approval (ETA) and the CE mark. The test data has been incorporated into the unique and recently revised MacRO software package that enables engineering professionals to calculate the performance of Steelgrid HR under a variety of slope stability conditions.

This paper will review existing meshes and full scale testing performed to date, provide design and installation guidance, examine the tests performed on Steelgrid HR mesh and mesh kit components and will also look into the details of the revised limit states approach version of the MacRO software package.

\section{Introduction}

Rock and soil slopes around the world are often found to exhibit instability. Additionally, the stability of both engineered and natural slopes can change over time. Rock slope instability is frequently characterised by bulging or movement of the material forming the face of the slope and this leads to the loss of material from the face typically in the form of a rockfall (Giacchetti et al., 2005). Causes can be related to internal factors concerning the rock mass; external factors concerning the rock mass; the local environmental conditions including surface/groundwater water, drainage, vegetation and weathering; anthropogenic factors and seismic activity (Higgins and Andrew, 2012).

The stability of soil slopes can require augmentation which can be achieved through the use of engineering products. Soil slopes may often contain large rocks which can weather free from the slope and represent a rockfall hazard to the area below. It is therefore not uncommon to see soil slope drapery for rockfall protection purposes. Soil nailing is a common methodology (BS 8006-2, 2011), used to artificially increase the slope angle of an engineered slope. In soil nailing projects geotechnical mesh products, used as flexible 
facings, work in cooperation with the soil nails in order to provide the required support to the surficial soil layer that is difficult to stabilise using only the nails (Giacchetti et al., 2010).

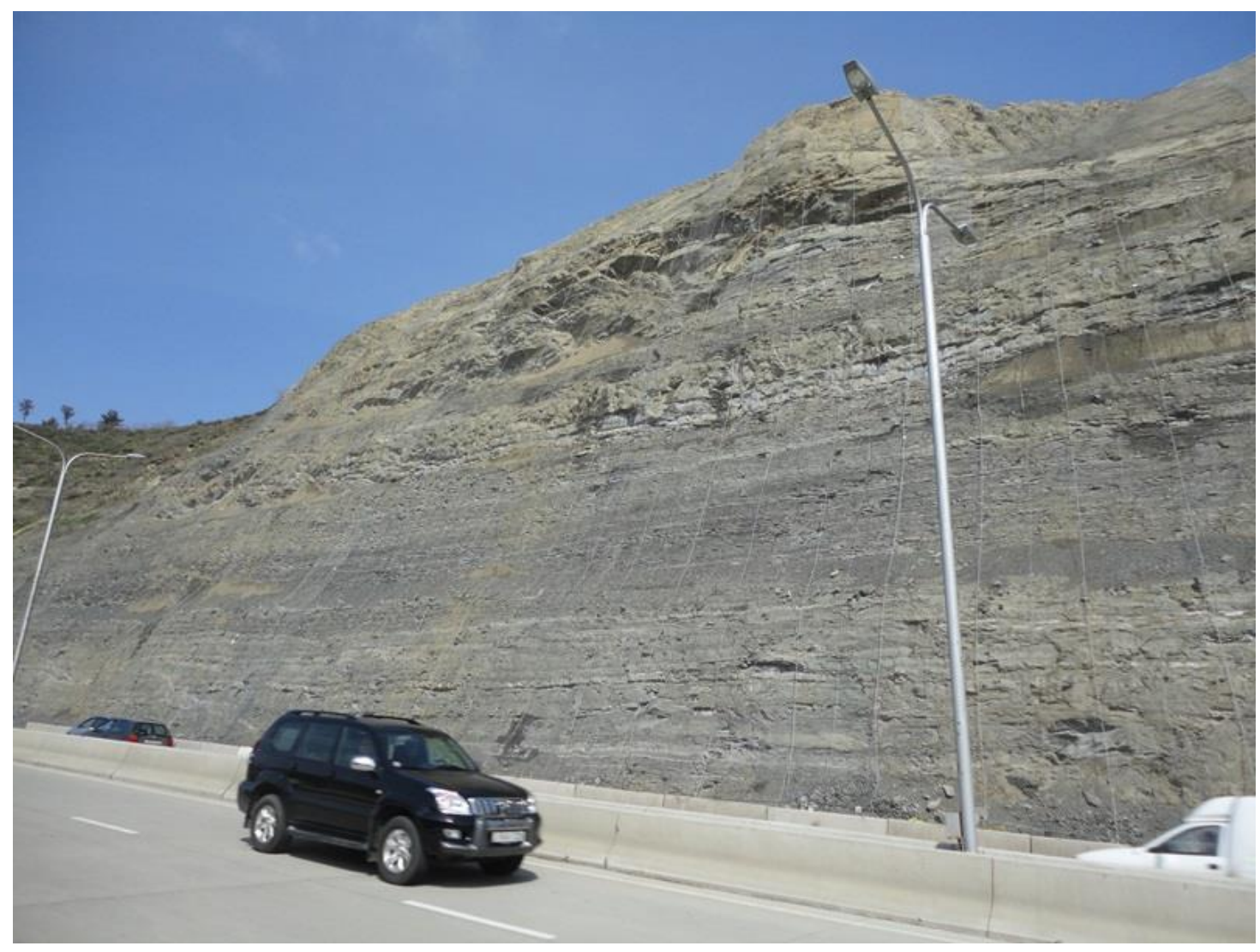

Figure 1 Rockfall protection offered to a road from a $90 \mathrm{~m}$ high unstable section of slope by Simple Drapery installation of Steelgrid HR mesh in Tbilisi, Georgia

Where rockfalls occur they can pose a risk to people and infrastructure (Figure 1 ) and the task then falls to engineering professionals to mitigate the identified risks (Hoek, 2000; Pierson, 2012) through the use of carefully selected (Pierson and Vierling, 2012) engineering products, whether mesh products, flexible 'catch' fences (Cantarelli et al., 2008; Gottardi and Govoni, 2009; Berends et al., 2011; Giacchetti and Zotti, 2012), reinforced soil embankments (Ronco et al., 2009; Brunet et al., 2009; Simons et al., 2010) or others such as Hybrid/Attenuator systems (Arndt et al., 2009).

For over sixty years the installation of slope covering mesh has been the primary option selected by designers and despite many developments of associated products rockfall mesh/rockfall netting is still one of the most common rockfall protection installation approaches in mining and civil engineering projects across the world.

\section{$2 \quad$ Mesh installation typologies}

Around the world; 'rockfall' mesh products are installed in one of two general ways: (1) 'Simple Drapery'/'Unsecured Drapery' and (2) 'Secured Drapery'/'Pinned Drapery' (Badger and Duffy, 2012).

Simple drapery installation (Giacchetti and Grimod, 2013) involves the covering of the slope using a continuous curtain of mesh that is anchored to the crest of the slope (Figure 2) with the crest rope and crest anchors forming a critical load-bearing part of the installation (Sasiharan et al., 2006). 


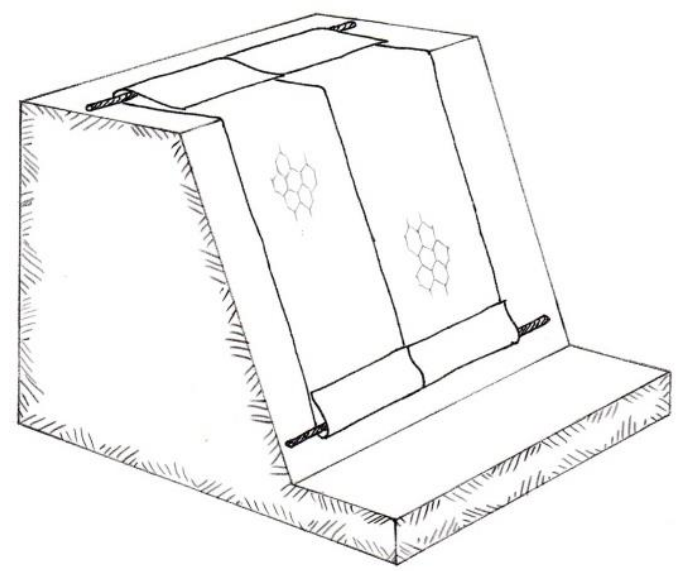

Figure 2 Simple drapery diagram showing crest line and toe line anchoring of the mesh

In simple drapery installations, the mesh may be anchored along the toe of the slope (Figure 3) or alternatively it may be weighted down and in some cases it will be left unsecured. As material falls from the slope face the mesh directs it down towards the toe of the slope in a controlled way. If the base of the mesh is free then the material will fall out onto the toe area below the mesh from where it can be cleared during maintenance works (Muhunthan et al., 2005). If the base of the mesh is restrained then the material will accumulate as a 'bulge' behind the mesh. This loading, combined also with any other loads including accumulation of snow will exert a long term load on the mesh and the magnitude of this load is used to determine the strength of mesh required. In order to prevent the debris bulge from becoming unacceptably large and impinging on activities or infrastructure below, a stiff mesh is considered to be of high importance (Bertolo et al., 2009) for a simple drapery installation.

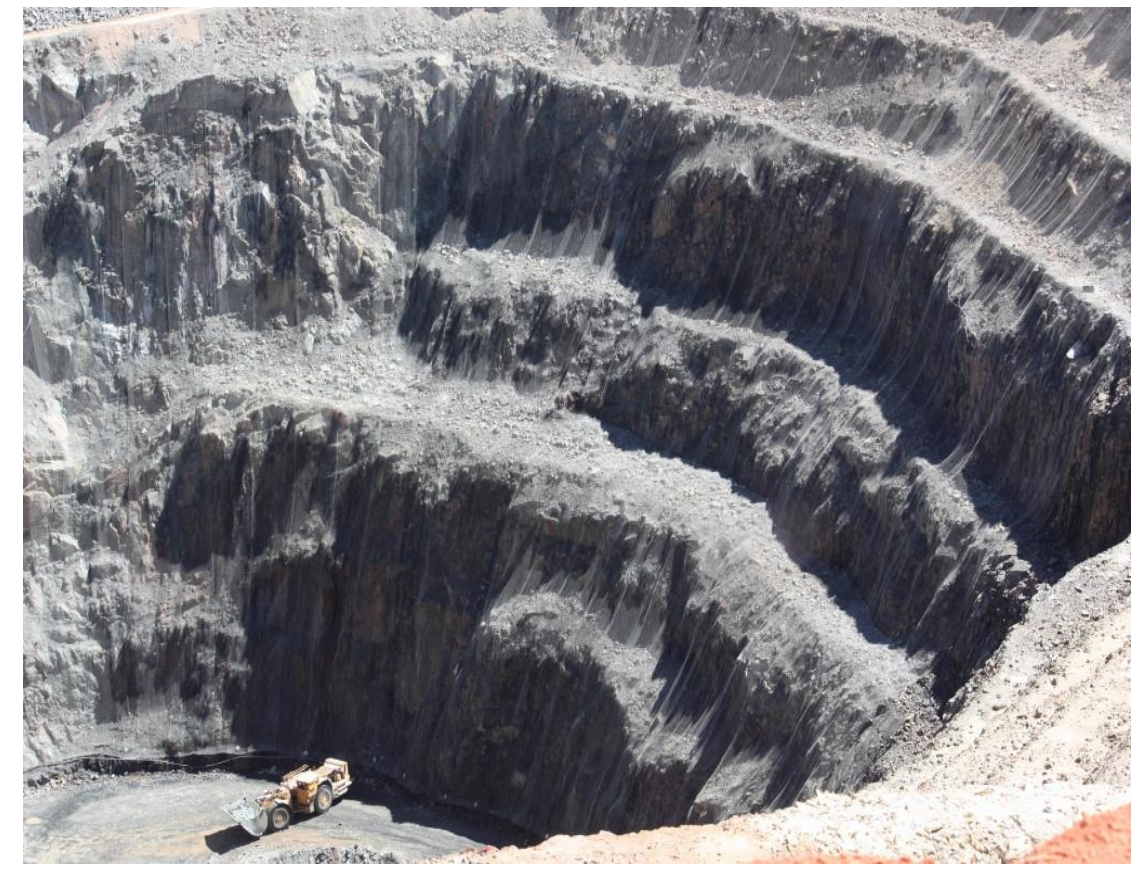

Figure 3 Simple drapery installation of Maccaferri double twist mesh, Rubicon Pit, Kalgoorlie

The second way to install the mesh is as a Secured Drapery/Pinned Drapery (Figure 4). In this type of installation the mesh is first installed as for Simple Drapery, then the secondary/face anchors are installed and the mesh held back against the slope face by anchor plates, sometimes used in combination with a network of ropes that form a regular pattern across the slope face (Figure 5). 


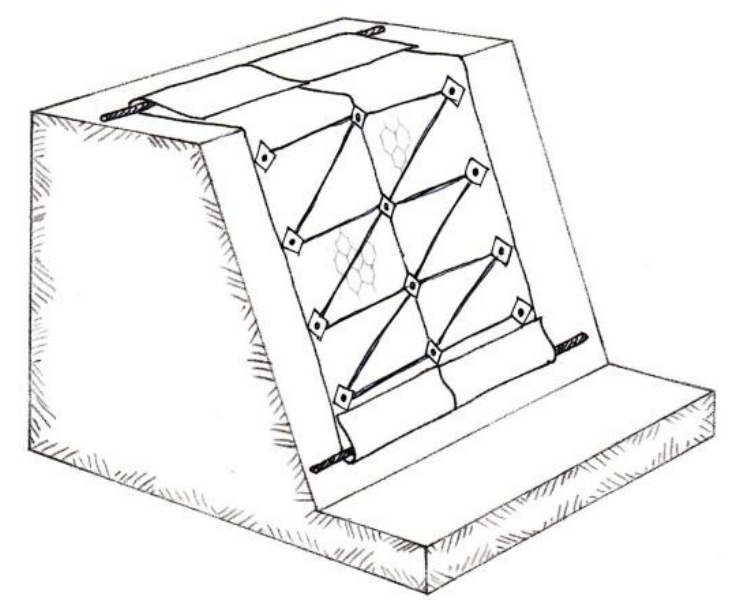

Figure 4 Secured drapery diagram showing the mesh anchored back against the slope face by a network of ropes and anchorages

A designer may choose to use a secured drapery for a variety of reasons including maintenance safety issues, available space at the base of the slope, irregular topography of the slope face (Figure 5), etc. In this type of application, one of the key objectives is to contain unstable or loose material in situ on the slope and prevent/limit it from moving from its original position (Badger and Duffy, 2012). In order to retain the material in place the mesh must be a stiff as possible - to exhibit the lowest possible outward deformation at small 'punching' forces (see Section 4).

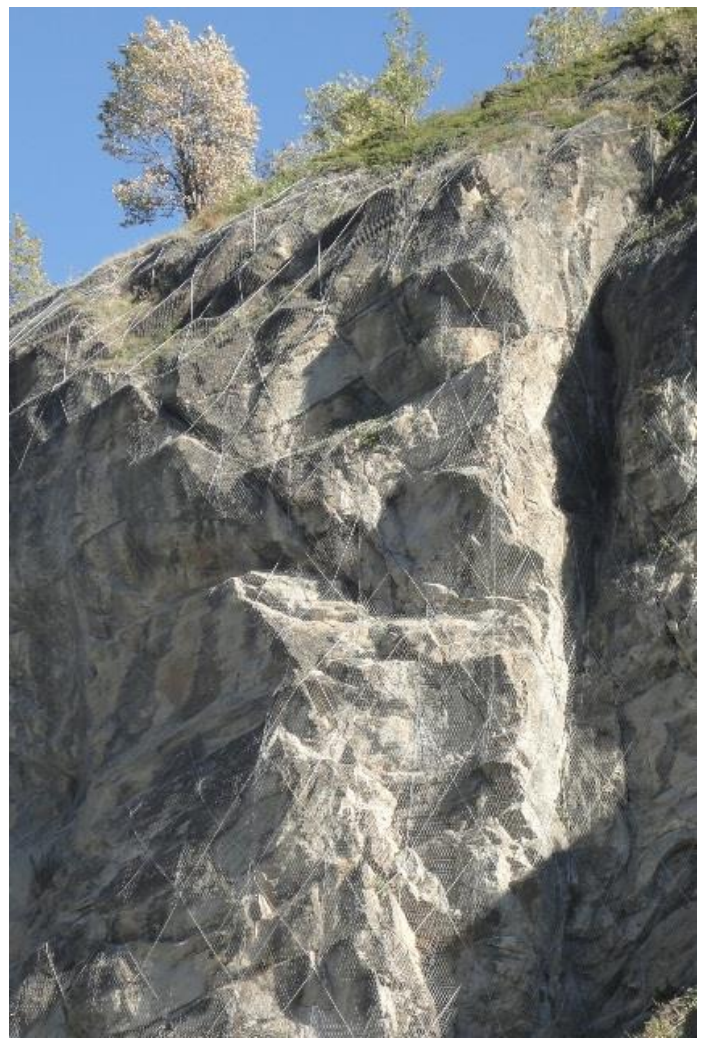

Figure 5 Secured drapery installation showing the mesh anchored back against the highly irregular topography of the slope face; Valle D'Aosta, Italy

Where secured drapery is used on soil slopes as part of a soil nailing project the mesh installation would be considered to be a soil nail facing (Giacchetti et al., 2011). In these applications, stiffness of the mesh facing is again of paramount importance. The mesh facing is the primary component of the installation that is acting to support the surface layers of the soil. As these layers begin to fail, the mesh, working together 
with the anchors, acts to resist the failure. It is therefore self-evident that a mesh which offers a greater stabilising effect at lower displacement - a stiffer mesh - is therefore more effective (Bertolo et al., 2009) for this application than a mesh that can only offer the same support at a greater displacement, even if its ultimate strength is high.

Geocomposite meshes can be engineered to offer this performance and Steelgrid HR is a good example. The extensive use of high tensile steel wire ropes in the mesh helps it to offer excellent stiffness that is reflective of the high stiffness of the component ropes with their ultimate strain of around only $6 \%$.

It should be noted that the literature contains theoretical work relating to the purported stabilising effects of meshes arising from their ability to 'actively' exert a [stabilising] force onto the surface of an unstable slope, thereby augmenting stability and reducing the likelihood of failure. Little evidence has been found for this effect - in geotechnically significant orders of magnitude - despite extensive field and laboratory based analysis by Maccaferri and others (Badger and Duffy, 2012, Section 3.1, pp. 569-570). It could therefore be concluded that consideration of mesh stiffness within a 'passive support' design is more important than a supposed active contribution within an 'active support' hypothesis.

\section{Geocomposite mesh kit}

In order to answer the needs of designers who are requiring higher and higher strength meshes, at the same time as providing for their needs of providing a high stiffness mesh, a geocomposite mesh called Steelgrid HR mesh has been developed.

Steelgrid HR is based on the hexagonal, double twist mesh technology but is accompanied by the inclusion of high tensile steel wire ropes to form an extremely high strength but also high stiffness mesh. An important and notable advantage of the inclusion of longitudinal ropes in drapery mesh was recently stated: "Their addition nearly eliminated the stress concentration on the mesh around the anchors." (Sasiharan et al., 2006). In addition to the evident stiffness effects, the presence of the interwoven steel wire ropes imparts an extremely high level of mechanical durability on the mesh and the ability to resist the kind of abrasive impacts that can often result from rock falls occurring behind the simple drapery installations used on the large slopes found in the open pit mining environment (Giacchetti and Grimod 2013).

The mesh is available in a range of strengths (Table 1 ) to ensure that a mesh with strength commensurate with load calculations arising from the engineers calculations is always chosen.

Table 1 Steelgrid HR meshes and nominal ultimate tensile strength (UTS) values

\begin{tabular}{cc}
\hline Steelgrid HR Variant & Ultimate Tensile Strength \\
\hline Steelgrid HR30 & $180 \mathrm{kN} / \mathrm{m}$ \\
Steelgrid HR50 & $125 \mathrm{kN} / \mathrm{m}$ \\
Steelgrid HR100 & $80 \mathrm{kN} / \mathrm{m}$ \\
\hline
\end{tabular}

This helps to eliminate over-specification of mesh products and gives the designer the opportunity to offer the appropriate mesh for the majority of applications. The variation of strength is achieved by controlling the spacing of the ropes and although this change modifies the strength of the mesh it does not notably change the stiffness/strain performance according to the European Technical Approval ETA: 13-0524. 


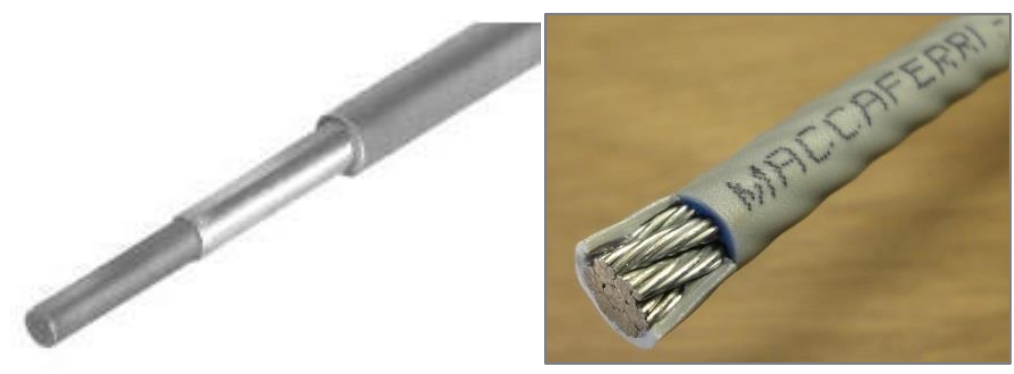

Figure 6 Detailed views of wire and rope, with Galmac and PVC coating, as used in Steelgrid HR PVC meshes

Corrosion protection is a basic requirement of all engineering designs and to meet the ever higher demands of modern engineering projects, all variants of the mesh are supplied with both wires and ropes coated with zinc/aluminium 5\% (Galmac) galvanising to Class A levels (EN10244-2 Table 2). For sites where corrosion is a significant problem, such as open pit mines where ground waters can be high aggressive, a second type of the mesh is available that have an additional, continuous coating of PVC (Figure 6) in addition to the zinc/aluminium galvanisation. The range of meshes is shown in Table 2:

Table 2 Full range of standard Steelgrid HR meshes

\begin{tabular}{cc}
\hline $\begin{array}{c}\text { Steelgrid HR } \\
\text { (Class A Zn/Al Galvanised Wires and Ropes) }\end{array}$ & $\begin{array}{c}\text { Steelgrid HR-PVC } \\
\text { (Class A Zn/Al Galvanised+PVC Wires and Ropes) }\end{array}$ \\
\hline Steelgrid HR30 & Steelgrid HR30-PVC \\
Steelgrid HR50 & Steelgrid HR50-PVC \\
Steelgrid HR100 & Steelgrid HR100-PVC \\
\hline
\end{tabular}

The use of a rope enhanced double twist based mesh (Figure 7) means that the advantages of double twist type mesh are retained in the new mesh whilst taking full advantage of the benefits of wire rope properties (Sasiharan et al., 2006). These advantages include the ability to fit the mesh easily onto the slope, the ability to cut, patch, join and repair the mesh as required (as with double twist mesh) and finally the classic 'unravelling resistant' behaviour and retention of strength in the event of damage.

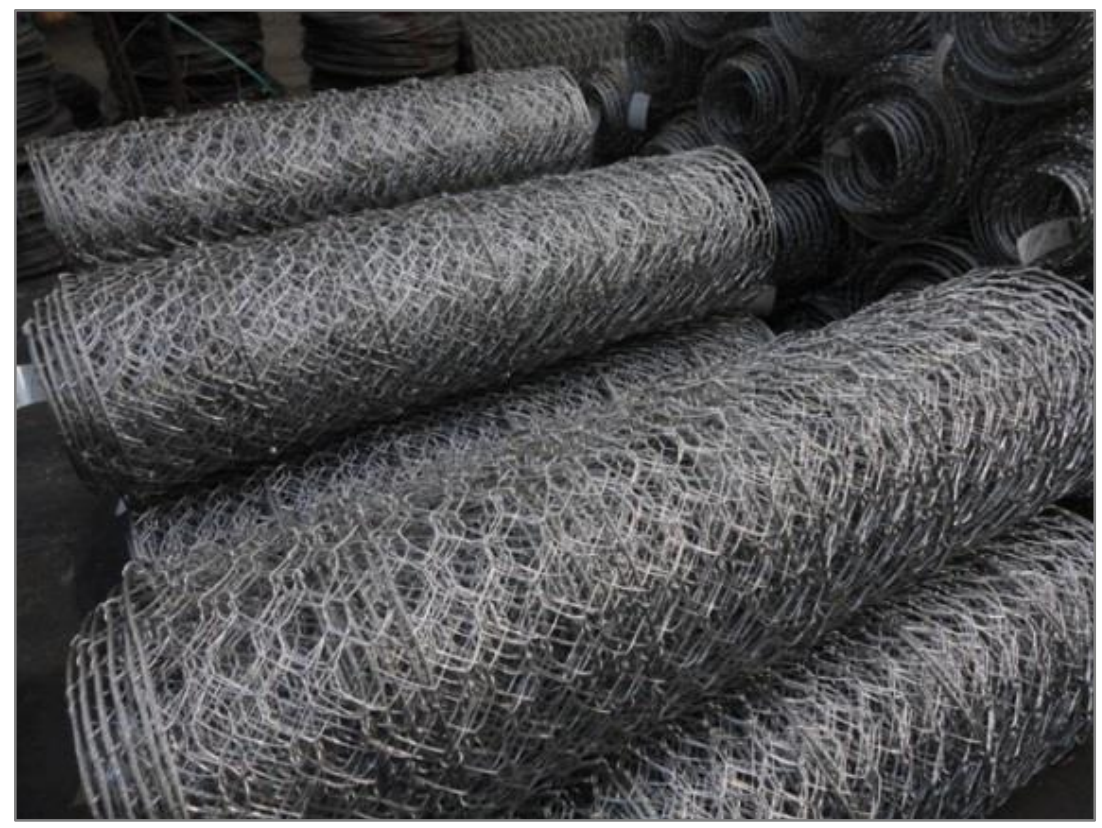

Figure 7 Steelgrid HR30 mesh rolls, with integrally woven wires clearly visible 
By virtue of its nature, it is necessary to follow certain simple but specific rules (see section 2) in order to install the mesh in the best way to achieve the optimum performance and thereby take full advantage of the properties of the mesh. To this end the mesh is supplied as part of a complete 'kit', featuring a range of tested accessories that are dedicated to making installation as quick, simple and effective as possible.

The accessories (Figure 8) include HR-Plate anchor plates for use in secured drapery applications, HR-Grip rope grips to connect the ropes over the crest/toe anchor ropes, HR-Link connectors to form the selvedge-selvedge connections and the HR-Caps which can be used with mesh in extremely aggressive environments. All of the accessories have been subject to extensive testing to ensure they are able to offer the optimum level of performance with and compatibility to the mesh.
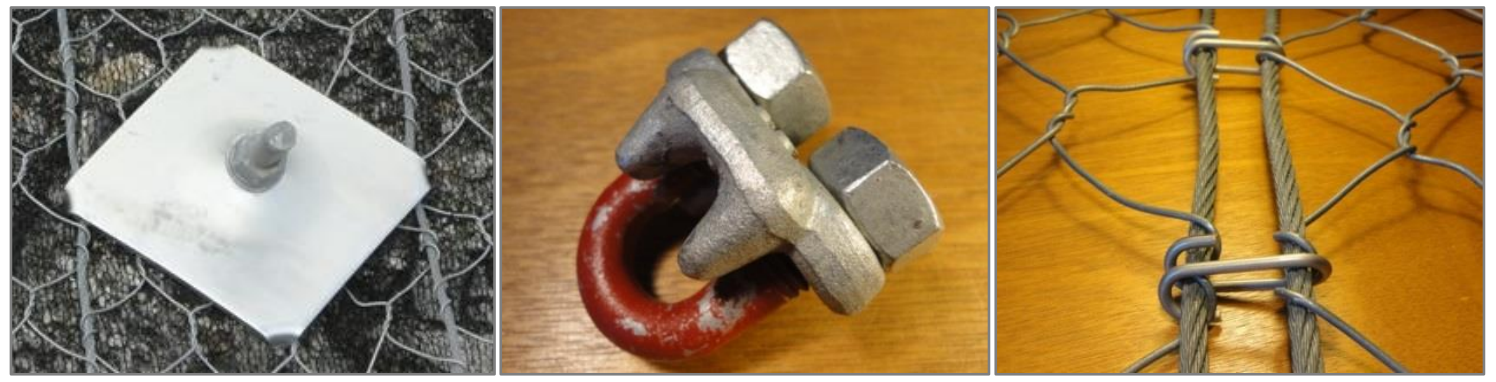

Figure 8 Accessory items listed from the left: HR-Plate anchor plate, HR-Grip rope grip, HR-Link selvedge connectors (shown in position joining two mesh panels)

The complete mesh kit enables installers to swiftly and easily install the Steelgrid HR mesh using similar techniques as for an installation of double twist rockfall netting but with minimal modifications to working method statements and risk assessments, which can be a considerable cost/time saving in many situations.

The mesh can be installed as a simple drapery or secured drapery and in the latter case the mesh is versatile and can be installed before or after (Figure 9) the installation of the slope face anchors; this can be a considerable advantage to the operational progress of the installation, especially on time sensitive works as is common in the mining environment. This feature is also useful on works carried out by small teams, typical of remote mining and infrastructure projects.

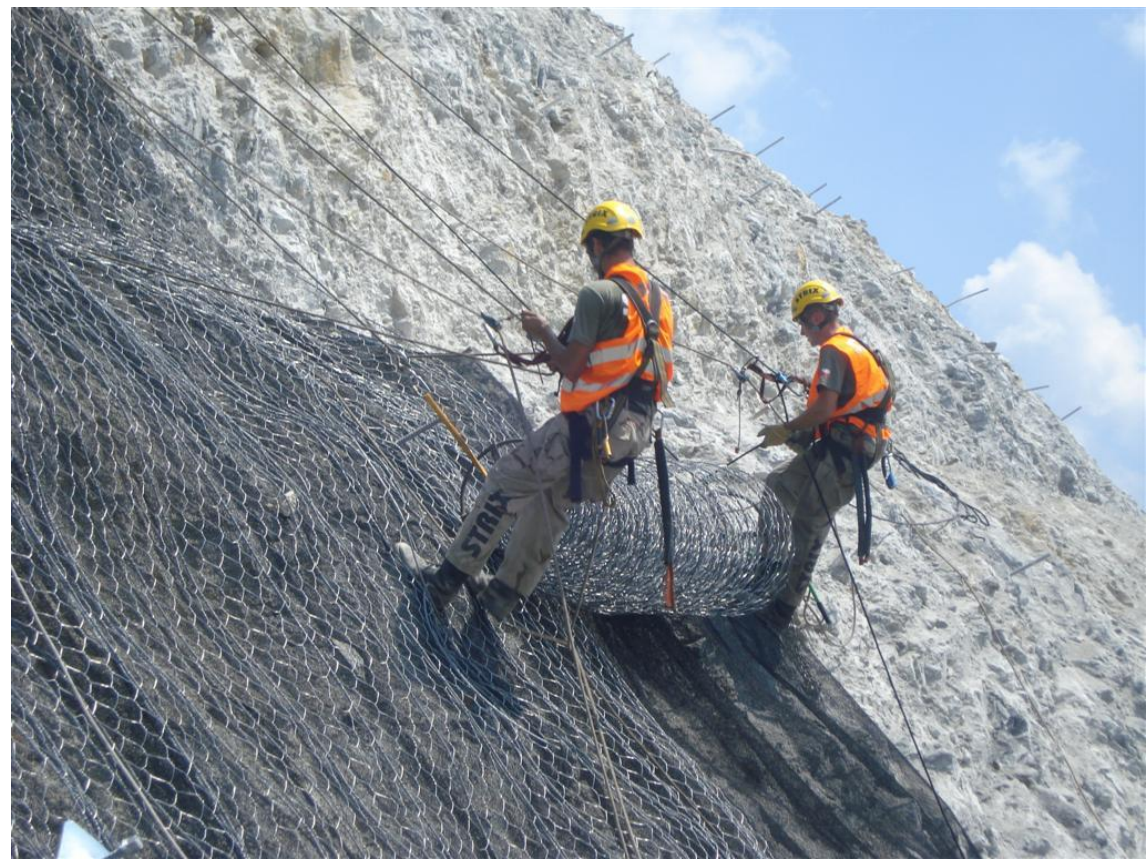

Figure 9 Installation of secured drapery Steelgrid HR30 kit (HR-Plate visible lower left) with mesh installed after the completion of anchoring operations 


\section{$4 \quad$ Mesh testing}

All of the meshes have been subject to a range of tests carried out by a number of highly respected third party technical testing bodies. The 'standard' range of tests have been performed in accordance with the new standard UNI 11437 (2012), including large sample tensile tests (Figure 10) and a new standardised punch test performed on $9 \mathrm{~m}^{2}$ samples (Figure 11) using a bespoke test apparatus. In addition, a range of industry standard (non-harmonised) tests have also been carried out according to the relevant protocols.

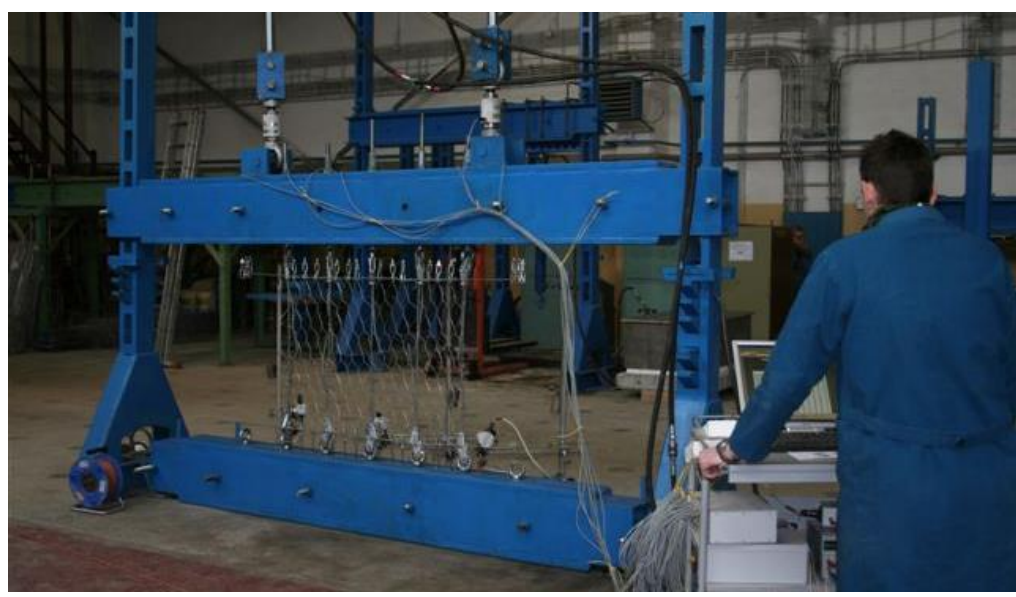

Figure 10 Computerised tensile testing on sample of Steelgrid HR30 according to UNI 11437 (2012) a particularly severe form of testing due to the lack of lateral mesh restraints

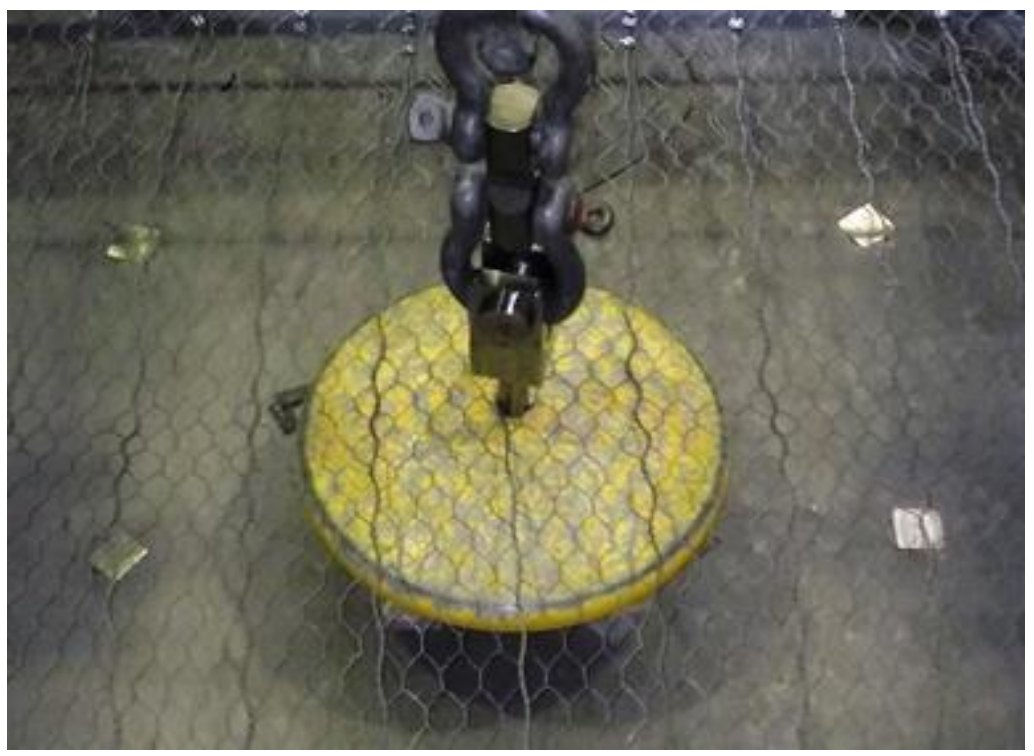

Figure 11 Computerised punch testing of Steelgrid HR30 sample $\left(9 \mathrm{~m}^{2}\right)$ according to UNI 11437 (2012)

The testing described was performed in accordance with a European harmonised standard (UNI 11437, 2012) and the results from this testing were collated and submitted to European Organisation of Test and Approval (EOTA). Assessment in accordance with the relevant processes has resulted in the kit (mesh + accessory components) being awarded the prestigious ETA.

Table 3 Sample performance values for Steelgrid $\mathrm{HR}_{3} \mathrm{O}$

\begin{tabular}{|c|c|c|c|c|}
\hline Mesh Type & $\begin{array}{l}\text { Ultimate } \\
\text { Strength }\end{array}$ & $\begin{array}{l}\text { Ultimate } \\
\text { Strain }\end{array}$ & $\begin{array}{c}\text { Punching Displacement } \\
\text { at } 15 \mathrm{kN}\end{array}$ & $\begin{array}{c}\text { Ultimate Punching } \\
\text { Strain }\end{array}$ \\
\hline
\end{tabular}




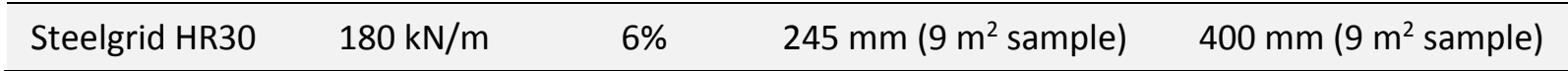

Another significant benefit of the EOTA approved testing process is that the results can be directly incorporated into the performance databases used by Maccaferri's in-house software package MacRO Studio, which is based upon observations made during innovative, in-house site-analogue tests (Bertolo et al., 2009), however the new data will have the advantage that they are derived from common, harmonised standards making comparison of meshes according to mechanical desirable properties a much easier process for engineers.

MacRO Studio is split into three sections, each of which is used to design a suitable mesh for a different type of installation: MacRO1, MacRO2 and BIOS.

MacRO1 (Figure 12) is based on the design of secured drapery for rock faces (Giacchetti and Bertolo, 2010). It assumes the cooperative function of mesh and anchors. The new limit state approach (Brunet and Giacchetti, 2012) allows the user to input geotechnical and geometric data, choose mesh from a menu, configure the anchor layout and properties and then select site-specific partial factors (with guidance on values from UNI EN 11211-4, 2012) before performing a verification check on the capacity of the anchorages, and mesh.

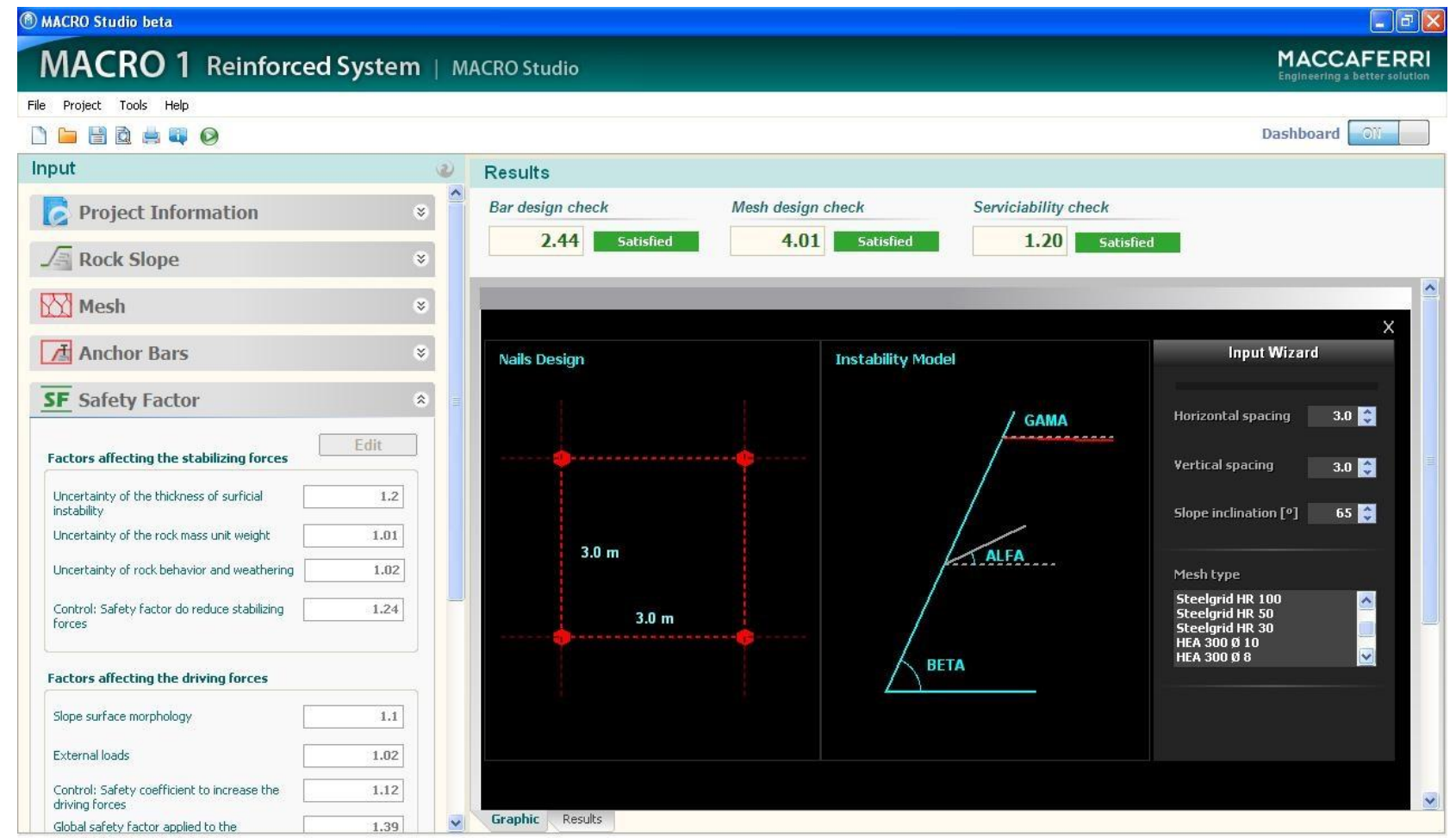

Figure 12 Screen shot of MacRO1 (secured drapery) section of Maccaferri's MacRO Studio rockfall design software package

The MacRO 2 (Figure 13) section of MacRO Studio is used for the verification of the performance of a mesh used in a simple drapery scenario (Giacchetti and Grimod, 2013). The programme's geotechnical foundations are the extensive and well regarded work of the Washington State Department of Transport (Muhunthan et al., 2005). The package has been revised to include a limit state style approach and includes the new ETA test data. The package now features a new catenary based calculation methodology which allows the user to design and then verify the performance of a crest rope and anchorage layout (Sasiharan et al., 2006) for the chosen simple drapery installation. 


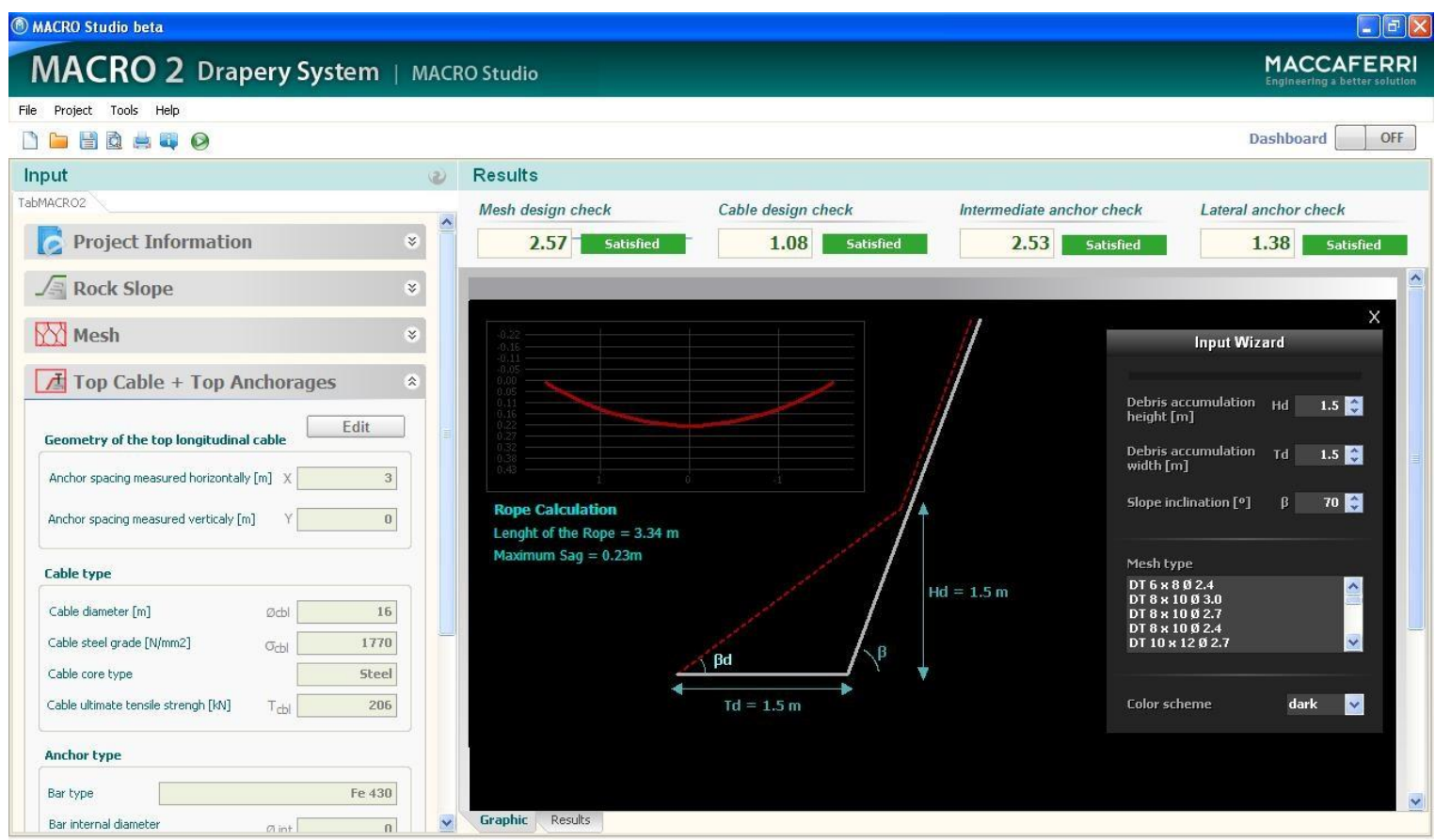

Figure 13 Screen shot of MacRO2 (simple drapery) section of the MacRO Studio rockfall design software package

The final section of the MacRO Studio package is BIOS (Giacchetti et al., 2011), designed for the verification of the performance of a mesh for use as a flexible structural facing for a soil nailed slope (Figure 14). The package checks both the ultimate limit capacity of the mesh (resistance to failure) and the serviceability limit capacity of the mesh (resistance to low stress bulging - in effect a stiffness check) for the given geotechnical conditions. The package uses partial factors from a user-defined table and is based upon the two part wedge method in general accordance with BS 8006 - Part 2 (2011). 


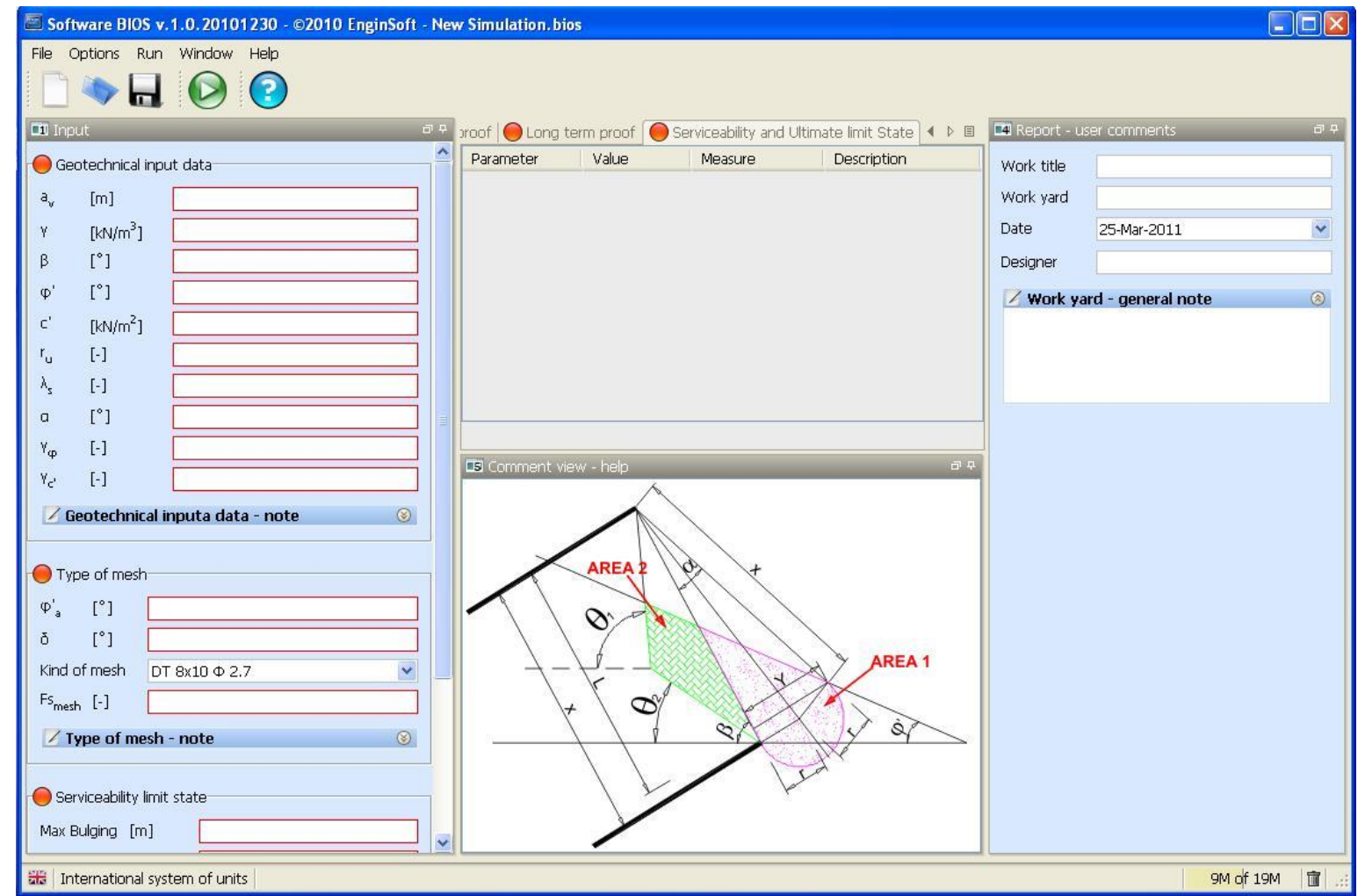

Figure 14 Screen shot of BIOS (flexible facing for soil nailed slopes) section of the MacRO Studio rockfall design software package

\section{$5 \quad$ Conclusions}

The new Steelgrid HR mesh kit forms a strong and versatile slope protection solution that is applicable to a broad range of rock and soil slope instability problems that are commonly encountered in both the open pit mining and civil engineering environments. The high strength and high stiffness mesh offers a high level of performance and its geocomposite construction offers a host of functional and practical advantages that are not possible from conventional mesh types. The mesh kit includes the geocomposite mesh, bespoke anchor plates and a range of specifically developed connectors. The mesh has gained the ETA and the mesh kit is complimented by the fully verified design software package MacRO Studio that, using ETA derived test data, allows engineering designers to calculate the performance of the Steelgrid HR meshes in three different types of stabilisation scenario: as a simple drapery on rock slopes, as secured drapery on both rock and soil slopes and as a structural soil nail facing.

\section{References}

Arndt, B., Ortiz, T. and Turner, A.K. (2009) Colorado's Full-Scale Field Testing of Rockfall Attenuator Systems, Transportation Research Circular E - C141. The Transport Research Board (TRB) of the National Academies, Washington, USA.

Badger, T.C. and Duffy, J.D. (2012) Rockfall Characterization and Control, The Transport Research Board of the National Academies, A.K. Turner and R.L Schuster (eds), The National Academy of Sciences, USA, Chapter 16, 'Drapery Systems' pp. 553-577.

Berends, J., Chaychuck, D. and Giacchetti, G. (2011) Techniques for reducing risk and increasing safety from rockfalls in open mines in Australia, in Proceedings 22nd World Mining Congress and Expo, Istanbul 2011, Vol. 1, pp. 563-569.

Bertolo, P., Oggeri, C. and Peila, D. (2009) Full-scale testing of draped nets for rock fall protection, Canadian Geotechnical Journal, Vol. 46, pp. 306-317.

Brunet, G. and Giacchetti, G. (2012) Design Software for secured drapery, in Proceedings Highway Geology Symposium, USA.

Brunet, G., Giacchetti, G., Bertolo, P. and Peila, D. (2009) Protection from High Energy Rockfall Impacts using Terramesh Embankments: Design and Experiences, in Proceedings 90th Highway Geology Symposium, September 2009.

BS 8006-2 (2011) Code of Practice for Reinforced Soils, Part 2, Soil Nail Design, viewed 16/08/2013, http://shop.bsigroup.com/en/ProductDetail/?pid=000000000030161660.

Cantareli, G., Giani, G., Gottardi, G. and Govoni, L. (2008) Modeling Rockfall Protection Fences, Nota Tecnica, Vol. 222, Distart, Universita Degli Studi Di Bologna. 
Giacchetti, G., Morandi, S. and Granito, A. (2005) Contributo della modellazione numerica nella progetta-zione della messa in sicurezza di una grande frana in roc-cia: il caso scascoli (bo) (The contribution of numerical modelling in the design of securing systems for a large rock slope failure in the case of Scascoli, Bologna).

Giacchetti, G. and Bertolo, P. (2010) Approccio al calcolo dei sistemi di reti con chiodi per il consolidamento delle pareti rocciose, Geoingegneria Ambientale e Mineraria (Calculation approach for mesh and anchor networks/systems for consolidation of rock slopes), Vol. XLVII (1), pp. 33-34.

Giacchetti, G., Grimod, A. and Cheer, D. (2011) Soil Nailing with flexible structural facing: design and experiences, in Proceedings Second World Landslide Forum, 3-7 October 2011, Rome, Italy.

Giacchetti, G. and Zotti, I.M. (2012) Design approach for rockfall barriers, in Proceedings XI CONGEO, Congreso Nacional de Geotecnia, Costa Rica, 9-10 August 2012.

Giacchetti, G. and Grimod, A. (2013) Design of simple drapery systems to guide rock falls along the slope, submitted to Eurock2013, www.eurock2013pwr.wroc.pl.

Grimod, A. and Giacchetti, G. (2012) New design software for rockfall simple drapery systems, in Proceedings World Mining Congress, Istanbul.

Gottardi, G. and Govoni, L. (2009) Full-scale Modelling of Falling Rock Protection Barriers, Rock Mechanics and Rock Engineering, 15 April 2009.

Higgins, J.D. and Andrew, R.D. (2012) Rockfall Characterization and Control, A.K. Turner and R.L Schuster (eds), The Transport Research Board of the National Academies, The National Academy of Sciences, USA, Chapter 2, 'Rockfall Types and Causes', pp. 20-55.

Hoek, E. (2000) Practical rock engineering (course notes), viewed 15 July 2013, www.rocscience.com/hoek/practical RockEngineering.asp.

Muhunthan, B., Shu, S., Sasiharan, N., Hattamleh, O.A., Badger, T.C., Lowell, S.M. and Duffy, J.D. (2005) Analysis and design of wire mesh cable net slope protection - Final research report, Washington State Transportation Commission - U.S. Department of Transportation - Federal Highway Administration.

Pierson, L.A. (2012) Rockfall Characterization and Control, A.K. Turner and R.L. Schuster (eds), The Transport Research Board of the National Academies, The National Academy of Sciences, USA, Chapter 3, 'Rockfall Hazard Rating Systems', pp. 56-71.

Pierson, L.A. and Vierling, M.P. (2012) Rockfall Characterization and Control, A.K. Turner and R.L Schuster (eds), The Transport Research Board of the National Academies, The National Academy of Sciences, USA, Chapter 1, 'Mitigation Selection', pp. 3-19.

Ronco, C., Oggeri, C. and Peila, D. (2009) Design of reinforced ground embankments used for rockfall protection, Natural Hazards and Earth Sciences, Vol. 9, pp. 1189-1199.

Sasiharan, N., Muhunthan, B., Badger, T.C., Shu, S. and Carradine, D.M. (2006) Numerical analysis of the performance of wire mesh and cable net rockfall protection systems, Engineering Geology, Vol. 88, pp. 121-132.

Simons, M.J., Pollak, S. and Peirone, B. (2010) Design and construction of a high energy rockfall embankment on the Trans-Canada Highway, in Proceedings of GEO2010, Calgary, Alberta.

UNI EN 11211-4 (2012) Rockfall protective measures: definitive and executive design, http://www.uni.com/index.php?option=com_content\&view=article\&id=1704:la-progettazione-delle-opere-di-difesa-dallacaduta-massi\&catid=111: generale\& Itemid=546.

UNI 11437 (2012) Opere di difesa dalla caduta massi - Prove su reti per rivestimento di Versanti, http://www.uni.com/index.php?option=com_content\&view=article\&id=1564:caduta-massi-e-reti-di-rivestimento-deiversanti\&catid=111: generale\& Itemid=546. 